\title{
ASSIMETRIAS DE PODER: GÊNERO, CLASSE E ETNIA EM DALCÍDIO JURANDIR
}

\begin{abstract}
RESUMO
O presente artigo tem por objetivo refletir acerca da condição e representação feminina no contexto sociocultural da Amazônia paraense no início do séc. XX, que se faz representar de maneira crítica na obra Três casas e um rio (1958), de autoria do escritor paraense Dalcídio Jurandir. O protagonismo da personagem negra dona Amélia, aqui eleita personagem central da discussão, e sua condição de subordinação e marginalização presente na narrativa, nos possibilita problematizar questões em torno da articulação entre sexo/gênero, entrecruzadas com outros eixos identitários, como classe e etnia, e sua influência nas práticas discursivas e sociais que sustentam desigualdades e exclusões que acometem muitas mulheres, produzindo assimetrias de poder entre os sujeitos. $\mathrm{O}$ aporte teórico utilizado nessa discussão pauta-se na Teoria Feminista e de Gênero, que subsidiarão a análise em torno do tema ora eleito objeto de estudo.
\end{abstract}

Palavras-chave: Assimetrias de poder. Gênero, classe e etnia. Três casas e um rio.

\section{ABSTRACT}

This article aims to reflect on the condition and representation of women in the socio-cultural context of the Paraense Amazon in the early XX, which is represented by Critical way in the work Three houses and a river (1958), authored by the writer from Paraná Dalcídio Jurandir. The protagonism of the black character Dona Amelia, here elected central character of the discussion, and its condition of subordination and marginalization present in the narrative, enables us questions about the articulation between sex / gender, intertwined with other identity axes, such as class and ethnicity, and their influence on discursive and social practices that support inequalities and exclusions that affect many women, producing asymmetriesbetween subjects. The theoretical contribution used in this discussion is based on Feminist and Gender, which will subsidize the analysis around the subject chosen here object of study.

Keywords: Power asymmetries. Gender, class and ethnicity. Three houses and a river. 
Ao tomar o conceito de gênero como marcador cultural de interpretação e validação de posições envolvendo homens e mulheres, os estudos em torno das representações sociais e de gênero na literatura de ficção, e também em outras produções artísticas e culturais, nos permitem, como afirma Silva (2010, p. 51), observar a representação "[...]da produção de valores e discursos historicamente construídos e validados em uma dada época", isso porque o texto literário, ainda segundo o autor, "[...]é um lugar de construção, validação, reprodução e subversão de identidades, de valores, de normas, de discursos". Assim, essa leitura contribui não só para reforçar ideias e propor mudanças, mas também nos ajuda na construção de um posicionamento político mais atualizado e consistente.

O estudo da representação feminina em obras que compõem o acervo da literatura amazônica é um tema ainda pouco explorado na atualidade, e que carece de pesquisas mais aprofundadas. Desde sua "descoberta", a Amazônia tem inspirado inúmeros textos repletos de mistérios e exotismos comum ao imaginário daqueles que buscaram/buscam descrevê-la sob uma visão exótica e misteriosa, berço de mitos e lendas, como se tornou conhecida no mundo, e ainda continua sendo divulgada pela mídia.

O escritor e crítico Jorge Tufic ${ }^{1}$ afirmar que a literatura produzida no norte do país, de um modo geral, ainda na atualidade carece de pesquisas mais aprofundadas. No ensaio intitulado "Existe uma Literatura Amazonense?" (1982), Tufic nos questiona, em especial nós, brasileiros, que trabalhamos e pesquisamos na área da Literatura e Cultura Amazônica, a respeito do nosso compromisso com o conhecimento e a divulgação dessa literatura, por sua importância e qualidade e, principalmente, seu legado sociocultural.

Quando se trata da descrição do espaço geográfico e das emergentes sociedades humanas que povoavam/povoam o território amazônico, e principalmente a representação da mulher dentro de uma perspectiva "regional", o exotismo tende a aflorar acentuando ainda mais as nuances entre classe, raça e etnia. Tais contradições costumam produzir estereótipos responsáveis pela discriminação e marginalização do Outro. A visão estereotipada em torno da mulher nativa é, de acordo com Heloisa Lara C. da Costa (2005), uma herança do período colonial na região, pois nessa época atitudes discriminatórias e depreciativas à mulher nativa eram típicas da elite estrangeira, sendo

1 Jorge Tufic é um dos nomes mais respeitados no cenário da literária amazônica. Além de escritor e crítico literário, é também membro da Academia Amazonense de Letras, da Academia Internacional Pré-Andina de Letras, da União Brasileira de Escritores, entre outros.

[...] muito frequente no registro dos viajantes a referência à lasciva e luxuria encontradas nas mulheres nativas. O espontaneismo sexual dessas mulheres indígenas e caboclas, na visão de estrangeiros, em sua maior parte, de formação calvinista, etnocentricamente era visto como imoralidade. Para uma elite regional que pretendia se afirmar perante o colonizador, cumpria se distanciar dessas formas de comportamento, utilizando-se de símbolos como roupas, joias, objetos de decoração, atitudes de recato que cumpriam o papel de diferenciá-las do resto da população empobrecida (COSTA, 2005, p. 152).

A representação de grupos marginalizados devido a condições políticas, sociais, raciais e culturais, é tema recorrente na literatura contemporânea, uma vez que a convivência entre pessoas de diferentes culturas e classes tende ao estabelecimento de relações por vezes assimétricas, nas quais o negro e o "nativo", evidentemente, ocupam lugares socialmente inferiorizados em relação ao modus operandi do colonizador, que explora as riquezas naturais e a força de trabalho local. O discurso de "diferenciação" imposto pela classe dominante, segundo Frantz Fanon, acentua as desigualdades existentes entre as partes, mostrando um mundo divido em dois, habitado por espécies diferentes, e com enorme diferença nos modos de vida, pois:

O servo é de essência diferente da do cavalheiro, mas uma referência ao direito divino para legitimar essa diferença estatutária. Nas colônias o estrangeiro vindo de qualquer parte se impõe com o auxílio dos seus canhões e das suas máquinas. [...]mas não são as fábricas nem as propriedades nem a conta no banco que caracterizam em primeiro lugar a "classe dirigente". A espécie dirigente é, antes de tudo a que 
vem de fora, a que não se parece aos autóctones, "aos outros" (FANON, 1968, p. 29-30).

Ao eleger como foco de discussão a representação da mulher no romance Três casas e um rio $(1958)^{2}$, de autoria de Dalcídio Jurandir, e as complexas relações de gênero entrecruzadas com os conceitos de classe e etnia, responsáveis por produzir assimetrias de poder entre os indivíduos, coloco no cerne da discussão a personagem d. Amélia, uma mulher negra e pobre que sofre o preconceito social e racial, não só por parte da família do Major Alberto, homem branco e viúvo com quem vive na condição de amasiada, mas também da sociedade cachoeirense.

O enredo da obra busca retratar um pouco da vida e dos costumes dos moradores da região de Marajó no estado do Pará. A maioria desses personagens, como assinala Freire (2006), são negros descendentes de cabanos ${ }^{3}$, e marcados por um preconceito que se apresenta no texto de maneira crítica. Nesse sentido, a discussão aqui proposta será desenvolvida sob dois aspectos principais, a saber: primeiramente analiso o espaço de atuação de d. Amélia no contexto das relações familiares, sua condição de mulher negra amasiada com homem branco, e sua relação com o filho mestiço, Alfredo, fruto da união com o Major Alberto; em seguida discuto sua condição de mulher e negra, discriminada e marginalizada, inclusive por outras mulheres, junto à comunidade cachoeirense.

\section{DALCÍDIO JURADNIR E A ESCRITA COMPROMETIDA COM O SOCIAL}

O escritor Dalcídio Jurandir nasceu em 1909, na Vila de Ponta de Pedras, situada na Ilha do Marajó, no estado do Pará. Atuou como romancista, cronista e jornalista. Foi militante comunista, sendo preso em 1936 e 1937. Faleceu no ano de 1979, na cidade do Rio de Janeiro. Ainda hoje o escritor é tido pela crítica especializada como um dos nomes mais consistentes da ficção de intervenção no norte do Brasil, com uma literatura atualizada e de aproximação com a realidade do homem amazônico.

Sua produção literária iniciou em 1941 e se desenvolveu numa sequência de onze obras publicadas: Chove nos campos de Cachoeira (1941), Marajó (1947), Três casas e um rio (1958), Linha do Parque (1959) ${ }^{4}$, Belém do Grão-Pará (1960), Passagem dos Inocentes (1963), Os Habitantes (1967), Primeira Manhã (1968), Chão dos Lobos (1968), Ribanceiras (1970), Ponte do Galo (1971). A qualidade literária de sua produção foi reconhecida pela Academia Brasileira de Letras, que em 1971 lhe concedeu o Prêmio Machado de Assis pelo conjunto da obra.

De acordo com Olinda Batista Assmar (2003), a escrita de Dalcídio Jurandir contextualiza-se dentro do regionalismo dominante à época da fase de afirmação gloriosa da ficção modernista brasileira, cujo fator impulsionador era tratar da realidade regional não só como movimento estético, mas também como mecanismo de denúncia das mazelas sofridas por homens e mulheres no meio que os circunda. Ao retratar episódios da vida amazônica permeada pela diferenciação entre classe e raça, seu olhar crítico buscou retratar as nuances e contradições capazes de produzir estereótipos responsáveis pela discriminação e marginalização do Outro, em especial da mulher, como veremos a seguir.

\section{ASSIMETRIAS DE PODER: GÊNERO, CLASSE E RAÇA EM TRÊS CASAS E UM RIO}

A diversidade de identidades e experiências derivadas da articulação sexo/ gênero, entrecruzadas com outros eixos identitários, como classe, raça, etnia, sexualidade, religião, territorialidade, participam de discursos e práticas que sustentam desigualdades e exclusões que acometem muitas mulheres em nossa sociedade, e produzem assimetrias de poder entre os sujeitos no âmbito das relações sociais, culturais e de gênero.

Com base nas contribuições dos estudos feministas aplicados ao texto literário, busco neste Artigo discutir como o preconceito e a discriminação, além de
2 Neste trabalho utilizo a $2^{\mathrm{a}}$. ed. revisada, publicada em 1979

3 Os "cabanos" formavam um grande número de revoltosos que lutaram pela independência do antigo Grão-Pará e Rio Negro, era composto pela camada pobre da sociedade: ex-escravos negros, índios deserdados e brancos pobres, que moravam em cabanas às margens de rios da região. A Revolta da Cabanagem, como ficou conhecida, ocorreu na região Amazônica entre os anos de 1835 e 1840.

4 Único romance que não pertence ao Ciclo do Extremo Norte. O contexto dessa obra se desenvolve a partir de uma pesquisa in loco do movimento operário no porto do Rio Grande do Sul, em 1958, destacando a organização e fortalecimento dos sindicatos e da deflagração de greves pelo movimento operário. A edição russa foi publicada em Moscou em 1962, com a apresentação de Jorge Amado. ISSN 1415-7950 da palavra 
desqualificar os sujeitos, são também motivadores de diversos conflitos sociais e humanos, principalmente quando se trata do ser feminino. À primeira vista, esse tipo de abordagem crítica pode parecer já superado dentro do próprio debate feminista, pois como nos aponta Adelaine LaGuardia (2015, p. 15),

[...] a preocupação com as formas como os homens representam as mulheres constituiu a primeira preocupação das feministas literárias, desde Virginia Woolf, que diagnosticou, em seu célebre livro intitulado "Um teto todo seu" (1929), a obsessão masculina pela mulher e as representações estereotipadas sobre ela feitas na grande maioria das publicações existentes na história humana. A pretensão daquelas estudiosas pioneiras era conhecer o lugar reservado à mulher no pensamento hegemônico masculino, como forma de compreender as razões de sua histórica opressão.

O romance Três casas e um rio (1958), aqui tomado como objeto de estudo, foi a terceira obra publicada por Dalcídio Jurandir, e considerado pela crítica como um de seus melhores livros. Seu enredo desenvolve-se a partir do próprio título, onde participam do espaço principal da narrativa três casas situadas às margens do rio Ararí, na vila de Cachoeira, ilha de Marajó, no estado do Pará, sendo elas: o chalé, residência da família do Major Alberto; a casa de Lucíola; e a sede da fazenda Morinantabalo, símbolo da ascensão e decadência latifundiária na região; além do rio, que possui grande importância no contexto da obra, e juntos figuram em permanente conflito.

Descendente de ex-escravos cabanos e órfã de mãe, na juventude d. Amélia amargou uma vida de miséria ao lado do pai, que vivia bêbado, perdido pelas ilhas próximas. Para sobreviver ela foi obrigada a trabalhar duro catando castanha, cortando seringa, apanhando açaí e gapuiava, e também dançando coco e isguetes.

Ao se amasiar ao Major Alberto, secretário da Intendência Municipal de Cachoeira, homem branco e viúvo, Amélia vivencia a distinção de papéis entre homens e mulheres no âmbito das relações familiares e de gênero. $\mathrm{O}$ sentimento de orfandade, desamparo e baixa estima expressos por ela, nos ajudam a perceber a naturalização de estatutos de submissão e marginalização que acometem a mulher negra e pobre que busca amparo junto a um homem branco numa sociedade patriarcal e sexista como a nossa.

O cotidiano no chalé se encarrega de delimitar o espaço e o adestramento do gênero no contexto familiar e social, cabendo a Amélia a rotina privada dos afazeres domésticos e o cuidado com os filhos. Já a função de Intendente legitima o espaço público como campo de atuação do marido, que costumeiramente, após o trabalho na Intendência, sesteava na rede da varanda entretido olhando os catálogos vindo da Europa, enquanto Amélia, sempre assídua e subserviente, lhe servia o café fresco.

Às vezes o Major Alberto emitia alguma informação extraída das revistas, como se ela, Amélia, acompanhasse seu raciocínio, e quando esta expressava uma opinião, ele entendia como troça, refletindo: "Que pensava aquela mulher, que sentia, que juízo fazia, e afinal porquê e quando começou ela a ter opinião em tais assuntos?" (D. J., p. 58) ${ }^{5}$, e concluía seu raciocínio cheio de superioridade: "Afinal, era difícil estar discutindo os acontecimentos do mundo com pessoa da natureza e condição da Amélia [...]” (p. 58).

Ao insinuar que a "natureza" da esposa não lhe permitia opinar a respeito

5 As citações extraídas da obra Três casas e um rio, de autoria de Dalcídio Jurandir, serão referenciadas ao longo do texto pela sigla D. J., seguidas do número da página citada.

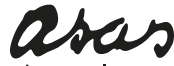

da palavra

VOL. $15 \mid$ N.1 1 JUL. 201 ISSN 1415-7950 de assuntos intelectuais e científicos, identifica-se nessa fala a efetivação de lugares socialmente diferenciados para o feminino e para o masculino no âmbito público e privado, no qual o homem branco e culto ocupa o espaço da civilização, evocado por suas atividades profissionais e intelectuais, enquanto a mulher, por oposição, é vista como o outro, ou seja, aquele que se opõem à civilização.

Essa definição pré-estabelecida de diferentes papeis entre mulheres e homens presente no contexto narrativo recai numa lógica dicotômica que, de acordo com Guacira Lopes Louro (2014, p.37), faz supor "[...]que a relação masculino-feminino constitui uma oposição entre um polo dominante e outro dominado", onde o exercício do poder se consagra em aspectos que parecem estar inscritos na "ordem 
das coisas", e assim instituem a formação identitária do indivíduo.

A disciplina "velada" praticada no espaço doméstico também pode ser entendida no âmbito das relações de gênero como instrumento de "fabricação das diferenças”, pois como nos orienta Foucalt, na conhecida obra Vigiar e punir,

A disciplina "fabrica" indivíduos; ela é a técnica especifica de um poder que toma os individuos ao mesmo tempo como objetos e como instrumentos de seu exercício. Não é um poder triunfante que, a partir de seu próprio excesso, pode-se fiar em seu superpoderio; é um poder modesto, desconfiado, que funciona a modo de uma economia calculada, mas permanente. Humildes modalidades, procedimentos menores, se os compararmos aos rituais majestosos da soberania ou aos grandes aparelhos do Estado. (1987, p. 153).

Um outro aspecto também muito relevante nessa relação entre Amélia e o Major, representada no romance em discussão, diz respeito à sexualidade da mulher negra, o que pode explicar de forma contundente o motivo pelo qual o Major a tenha escolhido como companheira, e também sua situação de submissão e insegurança no interior dessa relação, uma vez que o Major Alberto, na condição de viúvo, ansiava por uma vida mais tranquila e sossegada ao lado de uma mulher que cuidasse da casa, dos afazeres domésticos e que também tivesse "disposição na cama". Assim nascera entre eles uma espécie de entendimento (ou acordo) silencioso em que "misturava atração das peles, filhos, curtas reações do branco, o amor próprio da preta [...]" (D. J., p. 92).

Situações desta natureza, segundo Marco Frenette, retratam o quanto a mulher negra

[...] ocupa um lugar de destaque no imaginário do homem branco. Ela é, ao mesmo tempo, um objeto de desejo e um ser que está fora de seu campo de expectativas mais duradouras. $O$ exotismo que a cerca e a carga histórica que pesa sobre seus ombros limitam suas possibilidades de ação (2001, p. 35).

A "limitação de ações" e a falta de "perspectivas mais duradouras", de que nos fala Frenette, também perturbam a relação entre mãe e filho, que é marcada pelo preconceito ressentido de Alfredo, o filho mulato que deseja para si a brancura do pai como forma de aceitação social, pois não consegue construir uma imagem positiva da mãe que, embora seja amada como tal, por outro lado é rejeitada como símbolo de algo que ele rejeita em si mesmo. Apesar de sentir-se envergonhado por assim pensar, em seu íntimo Alfredo desejava que a mãe tivesse nascido "menos preta", menos subserviente, pois ao vê-la "ajoelhada a amarrar-lhe os sapatos como a empregada Sílvia fazia com os filhos do promotor", constatava que sua mãe "era sua escrava, preta escrava. As mãos dela trabalhavam com a ligeireza e a habilidade de uma mucama rendeira. Aquela cabeça baixa." (D. J., p. 102).

Alfredo se preocupava ao ver a união dos pais ameaçada pela presença da professora/normalista, uma moça branca, bem-educada, culta, e por isso considerada mais apropriada para ocupar o lugar de esposa do Major, que sentia-se "menos velho" e até lisonjeado com suas cartas cheias de "efes e erres"; enquanto a mãe parecia resignar-se a essa enxuta solicitude que ele tanto censurava: "Ninguém anda lhe empatando (dizia ela). Que arranje essa costela instruída. Que a professora assim como sai do quarto toda entonada pra aula, carregue também o bacio dele toda manhã, no inverno, como eu faço...” (D. J., p. 92, grifo nosso).

Revoltado com a situação de insegurança matrimonial vivida pela mãe, Alfredo temia que a professora "invadisse o chalé, apesar de sua educação, ou por isso mesmo, para tomar-lhe o pai, reduzir sua mãe a uma simples... Não, não sabia dizer o quê" (D. J., p. 96). Chegava a supor que a mãe, ciosa de sua cor e alheia a ambições, pouco ligava que fosse esposa ou esposarana do secretário, parecia não se incomodar com aquela situação "de intrusa e pronta a ser substituída. Não podia formular, quanto mais proclamar a situação humilhante: amasia, rapariga do Major, vivendo com o Major, mãe dos filhos do Major, cozinheira..." (D. J., p. 92).
9 [...] a língua na concepção dos sociolinguistas, é intrinsecamente heterogênea, múltipla, variável, instável e está sempre em desconstrução e em construção. [..] a língua é um processo, um fazer-se permanente e nunca concluído. A língua é uma atividade social, um trabalho coletivo, empreendido por todos os seus falantes, cada vez que eles se põem a interagir por meio da fala ou da escrita. (BAGNO, 2007, p. 36). 
Essa vulnerabilidade e "obscuridão" conjugal vivenciada pelos pais, refletida na falta de "perspectivas mais duradouras" e de "limitação de ações", pesava diretamente no destino de Alfredo, que sonhava ir para Belém estudar e ascender socialmente, tornar-se um homem respeitado, e poder "dar muitos vestidos à mãe" (D. J., p. 96), mas para isso necessitava da influência dela junto ao pai, e essa era sua maior preocupação ao vê-la triste, deprimida, sentindo-se rejeitada, com medo de ser trocada por uma mulher branca. Constatava que o esforço da mãe em ser aceita e valorizada por suas qualidades como boa dona de casa, cozinheira, lavadeira, parecia não ser reconhecido num mundo onde os valores dominantes eram brancos.

A convivência de d. Amélia com outros membros da comunidade cachoeirense também reforça a forma como as identidades são construídas ou "fabricadas", sua alteridade, o (não)lugar que ocupa no âmbito das relações sociais e de gênero, e como mulheres e homens se comportam face aos conceitos e padrões vigentes determinados ideologicamente. Nesse contexto, os padrões de feminilidade e masculinidade são muito significativos, assim como também aqueles relacionados à classe social e raça/etnia, que ao se cruzarem no campo das relações de gênero são capazes de gerar diversos cotnflitos relacionais mesmo entre as próprias mulheres.

"Era ou não era simples cozinheira, preta de pé rapado, trazida pelo Major para o pé das panelas?" (D. J., p 53), boatos desta natureza circulavam pela vila de Cachoeira expressando o despeito das senhoras brancas em saber que "a viuvez do secretário engordava nos pirões da cozinheira, sesteando nos braços da negra" (D. J., p 53). Tais falas expressam a inveja dessas mulheres em ver um homem de posição privilegiada como o Major Alberto vivendo amasiado com uma mulher negra e sem instrução.

Por outro lado, esse tipo de manifestações podem também ser interpretados como uma disputa de poder entre as próprias mulheres, em que a mulher branca e de classe mais privilegiada, por se julgar superior, sente-se afrontada com a união "ilegal" entre uma negra e um homem branco. Nesse tipo de situação, segundo Coutinho (2014), costuma ser comum a mulher negra ser descrita "como lasciva, elemento corruptor da ordem familiar, e representada de forma quase animalesca" (COUTINHO, apud SANTOS, NETO E CESÁR, 2014, p.30).

Concepções dessa natureza, conforme aponta Audre Lorde (1994), servem como pretexto para que um determinado grupo social sinta-se superior a outro, seja pela cor da pele ou pela etnia, e assim definirem a mulher em termos de sua própria concepção de valor e superioridade, enquanto as mulheres que diferem do padrão dominante tornam-se as Outras, as intrusas, as inferiores, criaturas exóticas, impedindo que sejam vistas como pessoas inteiras, como indivíduos, como seres humanos.

Diferente do despeito expresso pelas mulheres, entre os homens parece existir uma espécie de aprovação e cumplicidade a respeito do adultério masculino, como era o caso do Intendente, dr. Bezerra, que não só "aprovava" a união do Major Alberto com d. Amélia, como também, ao se queixar das exigências da esposa e das filhas em querer ostentar uma vida social de luxos e viagens, confidenciava em tom irônico ao amigo sua preferência pela cor morena, ao manifestar o desejo de "se meter num fundo de uma fazenda, aí pelo Goiapi, e ficar, cá entre nós, com uma caboclinha passando o cabelo por essa calva nua" (D. J., p. 64), e completava mais adiante: "Quero um colo farto, Major. Um colo mesmo cheirando a bezerro, a peixe, e tijuco de beira de rio. Mas farto, mas macio, amigo meu" (D. J., p. 65).

A partir da análise das experiências e relatos de homens brancos em busca de aventuras sexuais em locais distantes e considerados exóticos, Adriana Piscitelli (2002) afirma que nessas histórias a noção de "diferença" "está intimamente ligada ao erotismo - e vale assinalar que essa vinculação tem uma longa história nos relatos de viagem 'ocidentais', nos quais as viagens aos países do Sul são consideradas uma fonte de liberdade erótica" (PISCITELLI, 2002, p. 217).

Assim, ao analisar a representação da mulher negra no contexto do romance dalcidiano, enfatizo a necessidade de considerarmos a diversidade das identidades e experiências que constitui a identidade de mulheres e homens como participantes de 
compreender e discutir valores que se estruturam a partir da articulação do sexo/gênero com outros eixos identitários capazes de nos informar aspectos sociais, culturais e ideológicos que regem as complexas relações de poder entre os indivíduos, cujos discursos e práticas sustentam desigualdades e exclusões dentro do universo social e ficcional.

\section{CONSIDERAÇÕES FINAIS}

Problematizar a representação da mulher centralizada na personagem negra d. Amélia, e sua participação numa estrutura construída socialmente onde os fatores classe e etnia alimentam uma engrenagem opressora e discriminatória da mulher, nos faz perceber o quanto a diversidade de identidades e experiências derivadas da articulação entre sexo/gênero, entrecruzadas com outros eixos identitários como etnia, sexualidade, também participam de discursos e práticas que sustentam desigualdades e exclusões que acometem muitas mulheres em nossa sociedade, e produzem assimetrias de poder entre os sujeitos no âmbito das relações sociais, familiares e de gênero. Ao situar o presente estudo no âmbito da representação feminina e das relações de gênero, busquei problematizar a maneira como a personagem Amélia é construída e representada na obra, como interage com os homens - e também com outras mulheres - e o lugar de exclusão e subordinação que ocupa dentro das relações sociais e familiares. Porém, por se tratar de um texto de autoria masculina, há também que se considerar, em alguns momentos, a caracterização da personagem, e o papel que desempenha no enredo, como fruto de uma projeção do imaginário masculino.

Estudar as representações femininas no campo literário, e as formas como os sujeitos são marcados por questões de gênero, nos faz retornar ao pensamento de Antônio de Pádua D. da Silva (2010, p. 26), que nos ajuda a perceber como o uso de códigos selecionados e "postos em prática para tratar assimétrias e violências de um gênero em relação a outro" resulta em seu enquadramento histórico e social. Nesse sentido, reitero ainda a pertinência política de estudos dessa natureza, pois o texto ficcional em diálogo com a teoria feminista e de gênero nos possibilita atualizar a discussão em torno das condições sociais, raciais, políticas e culturais que acometem mulheres e homens em diferentes épocas e contextos.

\section{REFERÊNCIAS}

ASSMAR, Olinda Batista. Dalcídio Jurandir: um olhar sobre a Amazônia. Rio de Janeiro: Galo Branco, 2003.

COSTA, Heloísa Lara Campos da. As mulheres e o poder na Amazônia. Manaus: EDUA, 2005.

FANON, Frantz. Os condenados da terra. Trad. José Laurênio de Melo. Rio de Janeiro: Civilização brasileira, 1968.

FOUCALT, Michel. Vigiar e punir: nascimento da prisão. Tradução de Raquel Ramalhete, Petrópolis, Vozes, 1987.

FREIRE, José Alonso Torres. Entre construções e ruínas: uma leitura do espaço Amazônico em romances de Dalcídio Jurandir e Milton Hatoum. Tese (Doutorado em Literatura Brasileira), Departamento de Letas Clássicas e Vernáculas da Faculdade de Filosofia, Letras e Ciências, 244f. Universidade de São Paulo, São Paulo, 2006.

FRENETTE, Marco. Preto e branco. A importância da cor da pele. São Paulo: Publisher Brasil, 2001.

JURANDIR, Dalcídio. Três casas e um rio. $2^{\text {a }}$. ed. rev. Rio de Janeiro: Cátedra, 1979.

LAGUARDIA, Adelaine. Prefacio. In: SILVA, Joanna da. A mulher e o poder na ficção de Milton Hatoum. Curitiba: Appris, 2015. 
LORDE, Audre. Age, Race, Classe and Sex: Women Redefining Difference. In: Sister ousider. Bekerley. In: The Crossing Press, 1984.

LOURO, Guacira Lopes. Gênero, sexualidade e educação: Uma perspectiva pos-estruturalista. 16. Ed. Petrópolis, RJ: Vozes, 2014

PISCITELLI, Adriana. Exotismo e autenticidade: relatos de viajantes à procura de sexo. In.: Cadernos Pagu. São Paulo: Pagu - Núcleo de Estudos de Gênero - Unicamp, no. 19, 2002, pp. 195-231.

SANTOS, Daiana Brunetto Carlin dos, OLIVEIRA NETO, Marcolino Gomes de, CESÁR, Maria Rita de Assis. Sexualidades Contemporâneas: a (des)identidades de gênero e sexuais como resistência ou contraconduta. In: FERREIRA, JOVINO e SALEH. (orgs.). Um olhar interdisciplinar acerca de identidades sociais de raça, gênero e sexualidade. São Paulo: Pontes Editores, 2014.

SANTOS, Gislene Aparecida dos. Mulher negra-homem branco. Rio de Janeiro: Pallas, 2004.

SILVA, Antônio de Pádua Dias da. Mulheres representadas na literatura de autoria feminina: vozes de permanência e poética de agressão. Campinas Grande: EDUEPB, 2010.

Professora Adjunta no Instituto de Educação, Agricultura e Ambiente da Universidade Federal do Amazonas IEAA/UFAM, campus Vale do Rio Madeira. Doutoranda no Programa de Pós-Graduação em Literatura da Universidade de Brasília. Email: joannahumaita@bol.com.br; joanna-21@hotmail. com. 